\title{
Mainstream scientists confront unorthodox view of AIDS
}

\section{Washington}

Peter Duesberg's quest for scientific credibility for his unorthodox theories about the causes of AIDS lost ground on Saturday during a scientific forum on the aetiology of AIDS sponsored by the American Foundation for AIDS Research. Duesberg has challenged the idea that human immunodeficiency virus (HIV) causes the disease, and has outraged health-care workers by suggesting that AIDS patients abandon treatment with drugs meant to control the virus, and by claiming that infected heterosexuals need not use condoms or change their sexual practices.

Duesberg, a well-known virologist and professor of molecular biology at the University of California at Berkeley, has achieved a certain notoriety in the past year from his ideas, which originally appeared in the journal Cancer Research $(47,1199 ; 1987)$. They have been largely ignored by the scientific community, and have gained credibility mainly among patient populations with the greatest interest in learning that HIV infection does not lead inevitably to a fatal disease. But many researchers now feel that Duesberg's arguments must be confronted, as the consequences of acting on his advice may be fatal.

Because HIV does not seem to infect a high proportion of cells, Duesberg has claimed that it cannot cause the widespread changes in the immune systems of AIDS patients. He points out that most viral diseases appear before an antibody response is mounted, whereas AIDS symptoms always appear after antibodies to HIV have developed. He also raises issues about the latency of disease following infection, the apparent preference of the virus for homosexuals, and the difficulty in isolating HIV from all AIDS patients. Risky behaviour, not HIV, is the problem, according to Duesberg.

All of these points were disputed by the researchers present. William Haseltine of the Dana Farber Cancer Institute noted the distinction between antibodies that neutralize the virus and those that merely recognize it. Because the immune system can 'see' the virus does not mean that it can fight it off. Harold Ginsberg of Columbia University, who acted as moderator for the forum, explained that even when neutralizing antibodies are present, disease can still occur, as is the case with polio, measles and hepatitis-B virus.

Anthony Fauci, director of the National Insitute for Allergy and Infectious diseases, pointed out that HIV can be shown to be cytopathic in vitro, and that there are many ways in which it could orchestrate the slow decline in the immune system. He disparaged the idea that behaviour alone could cause AIDS, asking what risky behaviour a newborn infant could be said to have.

For his part, Duesberg seemed unwilling or unable to answer these potentially fatal objections to his theories and did not explain the relevance of risky life style to AIDS in Africa or to animal models of AIDS. Duesberg's behaviour theory also fails to explain why AIDS appeared only in the past decade. The scientists assembled at the forum appeared nonplussed that someone who professes unfamiliarity with modern immunology would choose to make such sweeping pronouncements about a disease that involves such complex and subtle changes in the immune system.

Duesberg's theories will no doubt continue to receive attention from groups already mistrustful of the scientific establishment's response to AIDS. But scientific acceptance for his ideas about AIDS, never very high, seems to be sinking.

Rebecca Ward

\section{High magnetic fields}

WEST Germany and France agreed last month to renovate and expand the highfield magnetic laboratory (HML) in Grenoble, France.

The laboratory is available to all researchers for the investigation of materials under extremely high magnetic-field conditions. Its current capacity of 30 Tesla (a European record) will be increased to 35 Tesla over the next few years through grants of DM12.5 million (about $\$ 7.5$ million) from both the West German Ministry for Research and Technology (BMFT) and the French Centre Nationale de la Recherche Scientifique (CNRS). HML has been operated jointly by the two countries since 1963.

S.D.

\section{China syndrome}

CHINA is to have a new 'special scientific zone' in the Zhongguancun area of the Haidian district of Beijing. Like the special enterprise zones (SEZs) already established in coastal regions, the new zone will offer special incentives to foreign partners. Although several of the existing SEZs include science parks and high-technology industries, the location of the new zone has been officially hailed not only as a new breakthrough in China's 'open' policy but also as the answer to China's hopes of its own 'silicon valley' (or 'silicon paddy') in the near future.

V.R.
Soviet scientific set-up attacked

\section{London}

THE Soviet Academy of Sciences, regarded in the West as a bastion of democracy, is failing to respond to the challenge of perestroika, according to a sharp attack by Professor Maxim Frank-Kamenetskii in Literaturnaya Gazeta. The article appeared on the eve of last month's Annual General Meeting (AGM) of the academy.

Frank Kamenetskii, who is a section head at the academy Institute of Molecular Genetics in Moscow, contrasts the open discussions of perestroika among professional groups such as writers, filmmakers and theatre workers with the complacency at the academy.

He complains that at last year's AGM, the proceedings followed "the same old scenario", with the vice-presidents simply reporting on "further successes".

Unlike factory workers who can now vote for their managers, FrankKamenetskii says, scientists employed by the academy have no part in decision making. Two years after the "reorganization" of the academy, interference by directors in the work of laboratories is still the norm. And the accreditation commissions introduced in 1986 to assess the work of scientists are, in practice. nominated by the director and serve simply to endorse his own decisions.

Frank-Kamenetskii attacks, either openly or by implication, several deeprooted features of Soviet scientific life: the false distinction of "our" science and foreign science, the poor quality of much Soviet published work and its poor showing in international citation indices.

Interestingly, though, the article rejects one of the "solutions" widely canvassed in discussions of recent educational reforms - the need to build up a research base in the universities and higher education institutes. Certainly, he says, the deficiencies of university research are a fault, but the victim is higher education, not research.

Frank-Kamenetskii argues that research establishments need not be vast concerns. The key, he says, is laboratory independence. Accepting that institutes may have to stand on their own feet, he asks that they be able to seek support from home and abroad and that they should be freed from what he calls the "scientific mafias", preferably by requiring that the administrators of research funds should serve only for limited periods.

Startlingly, Frank-Kamenetskii also urges that the appraisal of projects should include overseas referees. Anticipating the objection that this would lead to the premature leakage of discoveries, he says that it will not otherwise be possible to raise standards fast enough. Vera Rich 